NBER WORKING PAPER SERIES

\begin{abstract}
EXPLANATIONS OF EXCHANGE-RATE VOLATILITY
AND OTHER EMPIRICAL REGULARITIES IN SOME

POPULAR MODELS OF THE FOREIGN EXCHANGE MARKET
\end{abstract}

Robert P. Flood

Working Paper No. 625

\author{
NATIONAL BUREAU OF ECONOMIC RESEARCH \\ 1050 Massachusetts Avenue \\ Cambridge MA 02138 \\ February 1981
}

I would like to thank J. Bilson, M. Canzoneri, T. Glaessner, D. Henderson, N. Marion, K. Rogoff and other participants in seminars at Queens University and Rice University for many useful comments. Research assistance was provided by J. Withers. I would like to thank The National Science Foundation and the NBER Summer Institute in International Studies for support. This paper represents the views of the author and should not be interpreted as reflecting the views of the Board of Governors of the Federal Reserve System or other members of its staff. The research reported here is part of the NBER's research program in International Studies. Any opinions expressed are those of the author and not those of the National Bureau of Economic Research. 


\title{
Explanations of Exchange-Rate Volatility and other Empirical Regularities in some Popular Models of the Foreign Exchange Market
}

\begin{abstract}
$\underline{\text { ABSTRACT }}$
This paper is intended to accomplish two tasks. First, exchange-rate models of the sticky-price and flexible-price varieties respectively are checked for their consistency with two key empirical regularities: (1) the observed pattern of price-level vs. exchange-rate volatility, and (2) the observed pattern of spot exchange-rate vs. forward exchange-rate volatility. Second, a widely neglected reason for exchange-rate volatility, activist monetary policy is studied.

It is found that both sticky-price and flexible price models explain the empirical regularities rather well. Further, if prices are sticky it is found that exchange-rate overshooting may be empirically non-trivial.
\end{abstract}

Robert P. Flood

Board of Governors of the Federal Reserve System

Washington, D.C. 20551

(202) 452-3725 


\section{Introduction}

The widespread floating of exchange rates since 1973 has provided the first world-wide data for studying flexible-rate regimes in the postWWII era. The large volatility of exchange rates seen in these data created a natural scientific demand for on exchange-rate theory consistent with the new evidence. The beginnings of such a theory, which became known as the Asset Market Approach to Exchange Rates, emerged in 1976 in the work of Dornbusch (1976), Frenkel (1976), Kouri (1976), and Mussa (1976a). In particular, these authors offered explanations for why exchange rates may be expected to be more volatile than current underlying exchange-market fundamentals. $\underline{1}$ '

Dormbusch (1976): suggested that goods markets adjust slowly while asset markets (to a first approximation) adjust immediately. Since exchange rates are asset prices they adjust quickly compared with goods prices. With both goods prices and exchange rates entering asset markets, exrhange rates must bear a larger immediate burden of asset market adjustment, following a disturbance, than will be required once goods prices have begun to adjust. This was the celebrated overshooting result which has subsequently been refined by Frankel (1979), Frenkel and Rodriguez (1980), Mussa (1977); Rogoff (1979) and Wilson (1979):

The explanation offered by Frentel (1976), and Mussa (1976a) was that since current exchange rates reflect agents' belicfs not simply about. current market fundamentals but also about the entire future of such fundamentals, a disturbance to current fundmentals may be magnified in Its exchange-rate impact because of the disturbance's effect on beliefs 
about future fundamentals. This explanation was called the magnification effect and has been studied by Bilson (1978), (1979) and Meese and Singleton $(1980 a)$.

The explanation offered by Kouri (1976) was that a disturbance to current fundamentals may be magnified through its, affect on the current and expected future distribution of world wealth. This explanation has been studicd in linear models with rational expectations by Beyer and Hodrick (1980) and Flood (1979b).

It is useful to think of the Kouri view as one which endogenizes explicitly one of the elements of market fundamentals of the Frenkel-Mussa mode1. This is an interpretation pursued in the appendix. Because of the relative analytical difficulty of Kouri's model, magnification effects are discussed nere only for the Frenke1-Mussa mode1.

The present paper is intended to accomplish two tasks. First, models predicting overshooting and magnification respectively will be checked for their consistency with two key empirical regularities:

(i) the observed pattern of price-level vs. exchange-rate volatility,

(11) the observed pattern of spot exchange-rate vs. forward exchangerate volatility.

Second, a widely neglected reason for exchange-rate volatility, activist monetary policy, will be studied. 
Accomplishing the first task requires that we note that two important differences between the Dornbusch and the Frenke1-Mussa models are that Dornbusch's has sticky goods prices while Frenkel's and Mussa's have freely flexible prices, and Dornbusch distinguishes between domestic goods and other goods while Frenkel and Mussa deal only with a single aggregate commodity. In order to confront the pattern of exchange rates and price levels the Frenkel-Mussa model is expanded presently to distinguish domestic and other goods. In the context of this expanded model it is found that both the Dornbusch and the Frenkel-Mussa mode1s are consistent with observed data when the domestic share of the domestic good in consumption is greater than the foreign share of the domestic good in their consumption, and both models are inconsistent with the data when the above condition on consumption shares does not hold.

The second empirical regularity, which is that the spot exchange rate and forward exchange rates (of all maturities) tend to move closely together and thus have about the same degree of volatility is a striking fact which is not necessarily implied by either version of the moded... ent the differences in spot and 90 day forward rate volatility are explored for five industrial countries and the results are interpreted in terms of both the Dornbusch and Frenke1-Mussa versions of the model. In addition I examine the pattern of spot and forward rate volatility for the U.S.Canada rates for a forward maturity of 360 days.

The results here are suggestive of a methodology which may be useful in measuring the importance of exchange-rate overshooting.

The paper's second task is to argue that activist monetary policy contributes to exchange-rate volatility. In an example it is shown that if monetary policy is actually attempting to stabilize interest rates and if a monetary innovation is treated as uncorrelated with other disturbances in the economy then by ignoring the covariance of monetary innovations with other disturbances, exchange-zate volatility will be 
The organization of the paper is as follows.' In section II the two versions of the model are presented and solved. In section III both versions of the model are called on to explain the observed pattern of prices and exchange rates. In section IV both versions are challenged to explain simultaneously spot-rate volatility in excess of volatility in fundamentals and forward-rate volatility which is approximately the same as spot-rate volatility. Section $\mathrm{V}$ contains the argument that activist monetary policy exacerbates exchange-rate volatility.

II. Two Versions of a Two Commodity Exchange-Rate Model

The model presented in this section describes a country which is large only in the markets for its own money and its own output. Both a sticky-price and a flexible-price version of the model will be considered.

\section{The Mode1}

Money Market

$$
\begin{aligned}
m_{t}-\pi_{t} & =\alpha_{0}-\alpha_{1} i_{t}+\alpha_{2}\left(p_{t}+y_{t}-\pi_{t}\right) \\
\pi_{t} & =\theta_{p_{t}}+(1-\theta) q_{t}, 0 \leq \theta \leq 1 \\
i_{t} & =i_{t}^{*}+f_{t}-s_{t} \\
f_{t} & ={ }_{t}^{E s}{ }_{t+1}
\end{aligned}
$$

Goods Market

$$
\begin{aligned}
& y_{t}=\bar{y}=0 \\
& y_{t}^{d}=B_{0}-B_{1}\left(p_{t}-q_{t}\right)-\beta_{2}\left(i_{t}-i^{E}\left[\pi_{t+1}-\pi_{t}\right]\right)+w_{t}^{*}
\end{aligned}
$$




$$
\begin{aligned}
& p_{t}=p_{t}^{*}+s_{t} \\
& q_{t}=q_{t}^{*}+s_{t} \\
& t-1 y_{t}=t-1 y_{t}^{d} \\
& y_{t}=y_{t}^{d}
\end{aligned}
$$

\section{Exogenous Processes}

$$
\begin{aligned}
& m_{t}=m_{t-1}+v_{t} \\
& i_{t}^{*}=i_{t-1}^{*}+v_{t}^{*} \\
& w_{t}^{*}=w_{t-1}^{*}+u_{t}^{*} \\
& q_{t}^{*}=q^{*}=0
\end{aligned}
$$

Equation (1) describes money market equilibrium. In logarithms, money supply $\left(m_{t}\right)$ minus the price level $\left(\pi_{t}\right)$ equals real money demand, where money demand depends on the level of the domestic interest rate $\left(i_{t}\right)$ and the logarithm of real domestic income $\left(p_{t}+y_{t}-\pi_{t}\right)$, with $p_{t}$ and $y_{t}$ the logarithms of the domestic price of domestic ou tut and the quantity of domestic output, respectively. To simplify algebra I assume $\alpha_{2}=1$, which implies that (1) may be written as

$$
m_{t}-p_{t}=\alpha_{0}-\alpha_{1} i_{t}+y_{t} \cdot \underline{2}
$$

Equation (2) defines the price index $\left(\pi_{t}\right)$ with $\theta$ being the domestic consumption share of the domestic good and $q_{t}$ being the logarithm of the 
domestic price of the foreign good. Equation (3) states the covered interest parity condition with $i_{t}^{*}$ the level of the foreign interest rate, $f_{t}$ the one period forward exchange rate and $s_{t}$ the spot exchange rate. Equation (4) says that the forward rate equals the expected future spot rate, $t$ being the conditional mathematical expectation operator with information at time $t$ conditioning the expectation. The time $t$ information set, $\Omega_{t}$, is defined to include the values of all relevant variables dated $t$ or earlier and the values of the model's parameters. It follows that ${ }_{t}^{E x_{t+j}} \equiv E\left(x_{t+j} \mid \Omega_{t}\right)$ for any variable $x_{t+j} \cdot$

Recent empirical work on equation (4) has produced a mixed set of: results, with the weight of the evidence suggesting that (4) does not hold exactly 3 / In particular there may be a time-varying risk premium separating $f_{t}$ and $t^{E s} s_{t+1}$ (see Meese and Singleton (1980b)). $4 /$ However, such evidence does not contradict the assertion that (4) is a good approximation and a useful simplification in a study of exchange-rate volatility.

Equation (5) states that $y_{t}$ is a constant $(\bar{y})$, which is normalized to zero. Equation (6) gives the logarithm of aggregate demand for the domestic good $\left(y_{t}^{d}\right)$. This demand depends on the logarithm of the relative price of the domestic good $\left(p_{t}-q_{t}\right)$, the domestic real rate of interest $\left.\left(i_{t}-t^{E\left(\pi_{t+1}\right.}-\pi_{t}\right)\right)$, and $w_{t}^{t}$ a term summarizing aspects of foreign or domestic demand not eaptured elsewhere $5 /$ Equations (7) and (8) ensure that goods markets are arbitraged as $p_{t}^{*}$ is the foreign price of the domestic good and $q_{t}^{*}$ the foreign price of the foreign good.

Goods market equilibrium is described by (9a) or (9b) depending on whether prices are sticky or flexible. If prices are sticky, equation (9a) is the relevant goods market equilibrium condition. Conditional on $t-1$ 
information the price of domestic output for time $t, p_{t}$, is set at the level expected to clear the goods market during period t. Such pricing is purely anticipatory of events expected at $t$, but $p_{t}$ does not respond to actual events at $t$ and thus is predetermined. This type of pricing is a polar extreme of standard pricing rules. Mussa (1976b) and McCallum (1980): derive rules where pricing is partly anticipatory and partly dependent on past excess demand. $6 /$ In the Dornbusch model, pricing depends entirely on past excess demand. Thus, the present pricing rule and that of Dornbusch are extremes, which are spanned by the rules of Missa and McCallum. The extreme of purely anticipatory pricing has been adopted presently because of its analytical simplicity. Where appropriate, the modifications of the argument required for other sticky price rules will be indicated.

For flexible prices, equilibrium condition ( $9 b)$ holds. Here, $p_{t}$ is determined simultaneously with other variables during period $t$. Equations (10) - (12) specify $m_{t}$, i ${ }_{t}^{*}$ and $w_{t}^{*}$ to be first order autoregressive processes. For simplicity $i_{t}^{*}$ and $w_{t}^{*}$ are treated as random walks. Equation (13) states that the foreign-currency price of foreign goods $\left(q_{\hat{t}}^{*}\right)$ is a constant $\left(\bar{q}^{*}\right)$, which is normalized to zero. The variables $v_{t}$, v $v_{t}^{t}$ and $u_{t}^{*}$ are zero mean disturbance terms which are mutually and serially uncorrelated with finite variances $\sigma_{v}^{2}, \sigma_{v}^{2}$ and $\sigma_{u}^{2}$ respectively.

\section{Solutions}

The solutions of the two versions of the model for $s_{t}$ and $p_{t}$ are given below. 
Sticky Prices

$$
\begin{aligned}
& \mathbf{s}_{t}=\gamma_{10}+\gamma_{11} m_{t-1}+\gamma_{12} v_{t}+\gamma_{13} i \frac{*}{t-1}+\gamma_{14} v_{t}^{*}+\gamma_{15} w_{t-1}^{*}+\gamma_{16} u_{t}^{*} \\
& p_{t}=\gamma_{20}+\gamma_{21} m_{t-1}^{*}+\gamma_{22} v_{t}+\gamma_{23} i \frac{\omega}{t}-1+\gamma_{24} v_{t}^{*}+\gamma_{25} w_{t-1}^{*}+\gamma_{26} u_{t}^{*}
\end{aligned}
$$

Flexible Prices

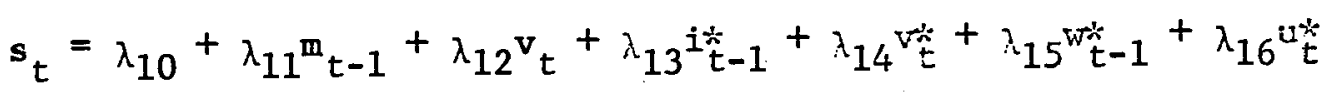

$$
\begin{aligned}
& \mathbf{p}_{t}=\lambda_{20}+\lambda_{21} \mathbf{m}_{t-1}+\lambda_{22} \mathbf{v}_{t}+\lambda_{23} i \frac{*}{t}-1+\lambda_{24} v_{t}^{*}+\lambda_{25} w_{t-1}^{*}+\lambda_{26} u_{t}^{*}
\end{aligned}
$$

where the $\gamma_{i j}$ and $\lambda_{i j}$ are expressed in terms of behavioral parameters in table I.

The sticky price solutions in table I were obtained from equations $(2)-(8)$, (14), price setting in accord with (9a) and exogenous processes (10)-(13): The solutions for the flexible price version also use (2)-(8), (14), and (10)-(13) but uses (9b) instead of (9a).

Note that the results of the sticky price version are similar to those of Dornbusch (1976), and Mussa (1977). If money follows a random walk $(\rho=1)$ then $\gamma_{11}=1$, implying the effect of a monetary disturbance on the exchange rate $\left(\gamma_{12}\right)$ must be greater than the disturbance itself, $\gamma_{12}=\frac{1}{\alpha_{1}}+1>1$. A similar result holds for $v_{t}^{*}$, the disturbance to $i_{t}^{*}$. Market fundamentals are defined presently to be the set of state variables $\Sigma=\left(m_{t-1}, v_{t}, i_{t-1}^{*}, v_{t}^{*}, w_{t-1}^{*}, u_{t}^{*}\right)$ which are the same for both versions of the model. $8 /$ 
TABLE I

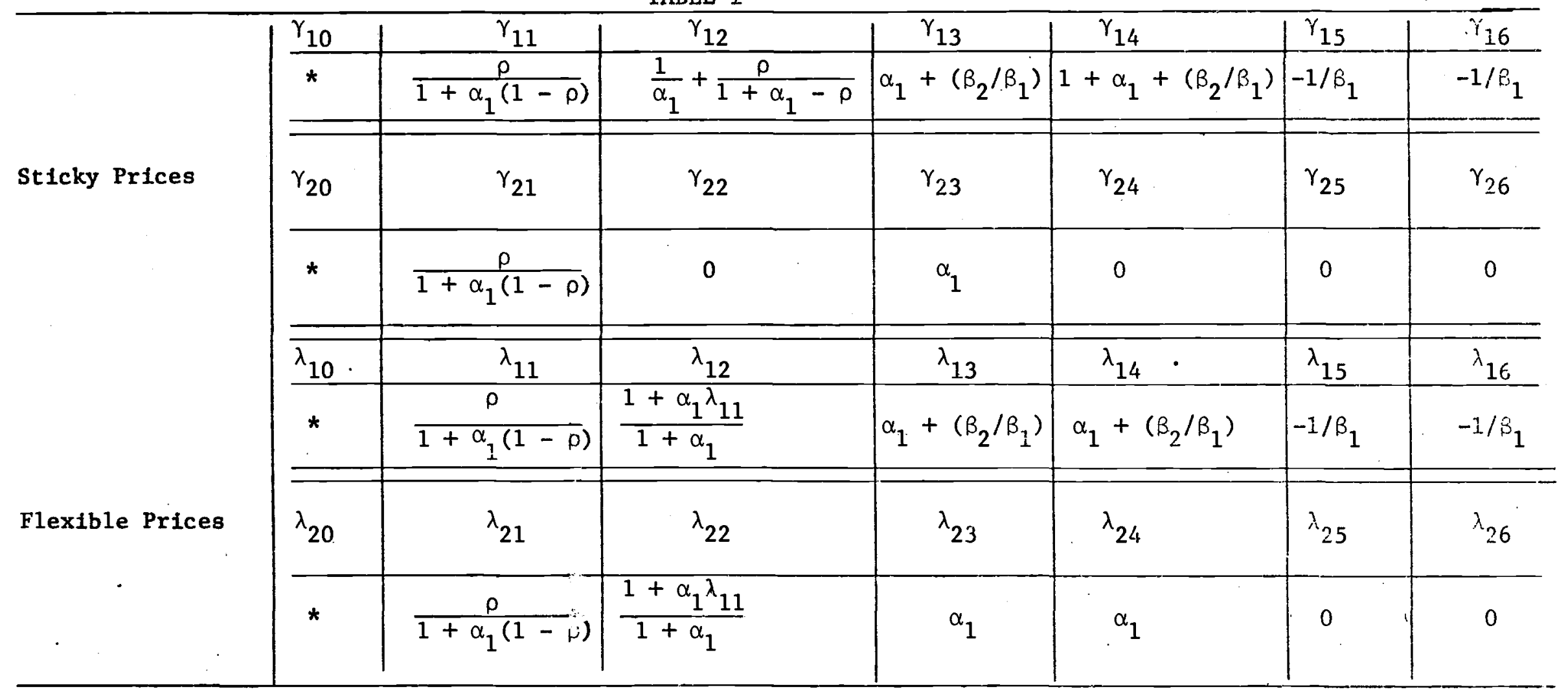

* Constant terms not reported 


\section{Volat1lity}

In the following sections the volatility of any variable $x_{t}$ is defined by

$$
t-1^{\operatorname{Var}\left(x_{t}\right)} \equiv{ }_{t-1} E\left[\left(x_{t}-t-1^{E x_{t}}\right)^{2}\right]
$$

where $t_{t-1} E x_{t} \equiv E\left(x_{t} \mid \Omega_{t-1}\right)$ and $\Omega_{t-1}$ is the $t-1$ information set which Includes all variables dated $t-1$ and earlier and the structure of the model. The present measure of volatility is a measure of predictability, which Frenkel and Mussa (1980, pp 374-5) argue to be ippropriate for exchange rates 9 /

\section{Exchange Rates and Prices}

Recent empirical work has found that exchange rates and national price levels (consumer prices or wholesale prices) do not follow closely the predictions of purchasing power parity. The relationship of prices and exchange rates was studied by at the macro-level by Frenkel (1980a), (1980b) and Krugman (1978), and was examined at a more micro-level by Kravis and ILpsey (1978), Isard (1977) and Magee (1978). These studies suggest that except for the most homogenous of products, different countries' outputs thould be treated as different products. This regularity has been embedded in the two versions of the model at hand by differentiating domestic and foreign goods.

Another regularity concerning prices and exchange rates is that exchange rates are more volatile than relative national price levels (C.P.I. or W.P.I.). This point was made by Stockman (1980), Frenkel (1980a) and Frenkel and Mussa (1980), and is documented for the current defirition 
of volatility in Table II. The results in Tabie II indicate that the ratio of spot rate volatility, $t-1$ VAR( $\left(s_{t}\right)$, to relative C.P.i. volatility, $t-1$ VAR(In[C.P.I.(i)/C.P.I.(j)]), range from a low of 5.76 ( $i=$ Japan, $j=$ Switzerland) to a high of 110.18 ( $i=$ U.S., $j=$ Switzerland). Thus, we require our exchange rate models to be consistent with exchange-rate volatility substantially in excess of reiative price level volatility. $10 /$ 
TABLE II

CANADA GERMANY JAPAN SWITZERLAND U.K.

$\begin{array}{lcccrr}\text { U.S. } & 16.60 & 54.76 & 15.58 & 1.10 .18 & 9.4 \\ \text { CANA.DA } & - & 43.39 & 15.21 & 53.30 & 7.01 \\ \text { GERMANY } & - & - & 11.17 & 18.54 & 20.19 \\ \text { JAPAN } & - & - & - & 5.76 & 13.51 \\ \text { SWITZERLAND } & - & - & - & - & 14.59\end{array}$

The entries in this table give the ratio of the sum of squared residuals in regression $S_{i j}$ to the sum of squared residuals in regression $P_{i j}$ where:

$i, j$ are counters over the country set (U.S., Canada, Germany, Japan, Switzerland, U.K.),

$S_{i j}$ is an ordinary least squares regression of the $\log$ of the mid-month spot exchange rate for month $t$ for countries $j$ and $j$ on $a$ linear trend and the information set $\Omega(i j ; t-1)$ which is the vector

$\Omega(i j ; t-1)=\{s(i j ; t-k), k=1,2,3,4 ;$

$f(i j ; t-k), k=1,2, j, i ; p(i ; t-k), k=1,2,3,4 ;$

$p(j ; t-k), k=1,2,3,4\}$,

where

$s(i j ; t-k)$ is tine lon of the ind-rontin spot excharise rate for countries $i$ and $j$ for month $t-k$

$f(i j ; t-k)$ is the $\log$ of the mid-month 90 day forward exchange rate for countries $i$ and $j$ for month $t-k$ 
$S_{i j}$ is defined in Table I

$P_{i j}$ is the ordinary least squares regression of $p(i, t)-p(j, t)$ on a linear trend and the information set $\Omega(i, j, t-1)$, which information set is defined. in Table I.

Data sources are reported in the appendix.

It is interesting to ask how well the two versions of the present model do in explaining exchange-rate volatility in excess of price-level volatility. The domestic price level is defined by equation (2) the foreign price level is given by 


$$
\pi_{t}^{*}=\theta * p_{t}^{*}+(1-\theta *) q_{t}^{*}, 0 \leq \theta * \leq 1
$$

where $\theta^{*}$ is the share of the domestic good in foreign consumption. Equations (2), (20), (7) and (8) may be manipulated to yield

$$
\pi_{t}-\pi_{t}^{*}=s_{t}+(\theta-\theta)\left(p_{t}-s_{t}-q_{t}^{*}\right)
$$

For the sticky price version, $p_{t}$ is predetermined and for both versions $q_{t}^{*}=\bar{q}=0$. It follows that for sticky prices,

$$
t-1 \operatorname{Var}\left(\pi_{t}-\pi_{t}^{*}\right)=\left[1+\theta^{*}-\theta\right]_{t-1}^{2} \operatorname{Var}\left(s_{t}\right)
$$

Thus, if $\theta>\theta$ (i.e. if home goods are a larger share of home consumption than of foreign consumption) $\left(1+\theta^{*}-\theta\right)$ is a fraction and the sticky price model has no difficulty in reconciling exchange-rate volatility in excess of price-level volatility.

We next turn to the performance of the flexible price version. Equation (22) was a special case holding for predetermined $p_{t}$. In general (with $\left.q_{t}^{*}=0\right)$

$$
\begin{aligned}
t-1 & \operatorname{Var}\left(\pi_{t}-\pi_{t}^{*}\right)=[1+\theta t-\theta]_{t-1}^{2} \operatorname{Var}\left(s_{t}\right)+[\theta-\theta *]_{t-1}^{2} \operatorname{Var}\left(p_{t}\right) \\
& 2[1+\theta-\theta][\theta-\theta *]_{t-1} \operatorname{Cov}\left(s, p_{t}\right)
\end{aligned}
$$

where ${ }_{t-1} \operatorname{Cov}\left(x_{t}, z_{t}\right) \equiv{ }_{t-1} E\left[\left(x_{t}-t_{t-1} E x_{t}\right)\left(z_{t}-{ }_{t-1} E z_{t}\right)\right]$ for any two variables $x_{t}, z_{t}$. To obtain an expression for price-level volatility with flexible prices, substitute the solutions for $s_{t}$ and $p_{t}$ into the right-hand side of (23). These substitutions yield 


$$
t-1 \operatorname{Var}\left(\pi_{t}-\pi_{t}^{*}\right)={ }_{t-1} \operatorname{Var}\left(s_{t}\right)-\psi_{1} \sigma_{v}^{2}+\psi_{2} \sigma_{u}^{2}
$$

where

$$
\begin{aligned}
& \psi_{1}=\left(\theta-\theta^{*}\right)^{2} \frac{2 \alpha_{1} \beta_{2}}{\beta_{1}}+\frac{\beta_{2}{ }^{2}}{\beta_{1}{ }^{2}}+(1+\theta *-\theta)\left(\theta-\theta^{*}\right) 2 \frac{\alpha_{1} \beta_{2}}{\beta_{1}}+\frac{\beta_{2}}{\beta_{1}} \\
& \psi_{2}=\frac{(\theta-\theta *)^{2}}{\beta_{1}^{2}}+\frac{2(1+\theta *-\theta)(\theta-\theta *)}{\beta_{1}^{2}}
\end{aligned}
$$

If $\theta>$ then both $\psi_{1}$ and $\psi_{2}$ are positive and the flexible-price version predicts exchange-rate volatility in excess of price-level volatility. The intuition behind this result is that disturbances which alter relative price ( $\left(w_{t}^{*}\right.$ and $v_{t}^{*}$ ) tend to improve relative price (increasing $p_{t}-s_{t}$ ) when appreciating the domestic currency (decreasing $s_{t}$ ) thus inducing a negatzve covariance of $s_{t}$ in (21) with the relative price term in (21). If $(\theta-\theta *)>0$ then this negative covariance unambiguously produces exchange-rate volatility in excess of price-level volatility.

Three points are demonstrated in the analysis of this section. First, both the sticky-price and flexible-price versions of the model predict exchange-rate volatility in excess of price-level volatility when the share 
of domestic goods in domestic consumption is greater than the share of domestic goods in foreign consumption. Second, deviations from purchasing power parity, which may be obstained from equation (21), show persistence if relative price changes show persistence whether prices are sticky or flexible. For example, for flexible prices and the exogenous processes presented here $p_{t}-s_{t}$ (the terms of trade) follows a random walk implying (for $\theta \neq \theta *$ ) that $\pi_{t}-\pi_{t}^{*}-s_{t}$ also follows a random walk. Third, both versions predict a negative correlation of innovations in $s_{t}$ and innovations In the terms of trade $\left(p_{t}-s_{t}\right)$. For the sticky price version, the correlation arises because exchange-rate innovations are innovations in the terms of trade. In the flexible-price version the correlation arises because things which tend to improve the terms of trade (positive $u_{t}^{*}$ negative vit) tend to appreciate the domestic currency. 11 '

IV. Exchange Nate Volatility in the Spot ard Forward Excharan Markets Studying the time series behavior of spot exchange rates Meese and Singleton (1980): found that they could not reject the hypothesis that exchange rates follow a random walk around a linear trend. This hypothesis is formalized as

$$
\begin{aligned}
& s_{ \pm}=B_{0}+B_{1} t+s_{t-1}+\varepsilon_{t} \\
& \mathbf{E}\left(\varepsilon_{t} \varepsilon_{t-1}\right)=0, i \neq 0 .
\end{aligned}
$$

When (27) and (28) are combined with the additional assumption

$$
t-1 E\left(\varepsilon_{t+1}\right)=0 \quad 1=0,1,2 \ldots
$$


the following may be deduced

$$
\frac{t-1^{\operatorname{Var}\left(t^{E} s_{t+j}\right)}}{t-1^{\operatorname{Var}\left(s_{t}\right)}} \approx 1 ; j=0,1,2, \ldots . .
$$

Equation (30) states that the volatility of any expected future spot rate and the current spot rate are approximately equal.

To the extent that forward rates are equal to expected future spot rates, equation (24) matches closely the regularity noted by Mussa (1979, page 14) that "For all maturities of forward contracts, the day-to-day (or week-to-week or month-to-month) change in the forward rate. is always very close to the day-to-day (or week-to-week or month-to-month) change in the contemporaneous spot rate." Mussa's observation and equation (24) match the regularity reported in Table III, which provides measures of $t-1 \operatorname{Var}\left(f_{t+3}\right) t_{t-1} \operatorname{Var}\left(s_{t}\right) .12 /$ In the rest of this section of the model will be calied on to explain the regularity reported in Table III. First, expressions for both sticky prices and flexible prices will be developed for $t-1 \operatorname{Var}\left(s_{t+j}\right) /_{t-1} \operatorname{Var}\left(s_{t}\right)$. Second for hypothetical (but perhaps reasonable) values of the relevant behavioral parameters the values of these expressions will be compared with the values in Table III. 
TABLE III

CANADA GERMANY JAPAN - SWITZERLAND U.K.

$\begin{array}{lccccc}\text { U.S. } & 1.05 & .99 & 1.07 & 1.01 & 1.22 \\ \text { CANADA } & - & 1.05 & 1.07 & 1.03 & 1.15 \\ \text { GERMANY } & - & = & 1.07 & .95 & 1.10 \\ \text { JAPAN } & - & - & - & 1.03 & 1.07 \\ \text { SWITZERLAND } & - & = & = & = & 1.13\end{array}$

The entries in this table give the ratio of the sum of squared residuals in regression $S_{i j}$ to the sum of squared residuals in regression $F_{i j}$, where:

$S_{i j}$ is a regression defined in Table II and $F_{i j}$ is an ordinary least squares regression of the $\log$ of the mid-month 90 day ( 3 month) forward exchange rate for month $t$ for countries $i$ and $j$ on a jịnear trend and the information set $\Omega(i j ; t-1)$, which is defined in Table II. Data sources are reported in the Appendix. 
The Sticky-Price Version

Equation (14) may be rewritten as

$$
\mu_{t}-p_{t}=-\alpha_{1}\left({ }_{t}^{E s} s_{t+1}-s_{t}\right)
$$

Where $\mu_{t}=m_{t}+\alpha_{1} i_{t}-y_{t}$. For the sticky price version, $p_{t}$ is predetermined and hence disturbances which are felt through $\mu_{t}$ (such as current monetary disturbances) must unexpectedly alter the forward prenium, $t^{E s} t_{t+1}-s_{t}$. Unexpected changes in $t_{t+1}^{E s_{t}}-s_{t}$ obviously require different unexpected shanges in $t_{t+1}^{E s}$ and $s_{t}$ and thus different volatility.

The sticky-price version of the model illustrates an example of this point. For the sticky-price version use (15) to calculate

$$
{ }_{t-1} \operatorname{Var}\left(s_{t}\right)=\left(\frac{1}{\sigma_{1}}+\gamma_{11}\right)^{2} \sigma_{v}^{2}+\left(1+\gamma_{13}\right)^{2} \sigma_{v}^{2}+\gamma_{15}^{2} \sigma_{u}^{2}
$$

and

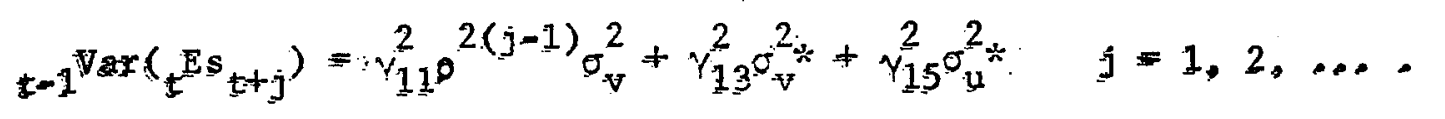

In this version, the spot rate is unamigously more volatile than the one step ahead expected futuxe spot rate $(j \equiv 1)$. Further, if 0 is in the range

$-1 \leqslant p \leqslant 1$ then the spot rate is more volatile than al1 expected future spot rates, and if $|\circ|>1$ then for j greater than some integer, expected future spot rates must be moxe volatile than the surrent spot rate. Sticky-price models norma1ly exhibit exchange-rate overshooting. An exchange rate is said to overshoot when its imediate response to disturbance is laxger than some benchaxk response (Flood (1979b)). For sticky-price model the appropriate benchmark is the exchange-fatets Inkediate response conditional on prices being freely flexible. Furthex, sticky price models share the aspect that the forward prentim must adjust to accomodate disturbances to current money-market fundamentals. 
The model at hand is special in that with purely anticipatory pricing, the goods market is currently expected to be in equilibrium next period and to remain in equilibrium indefinitely. Thus, the economy is expected to attain its long-run or benchmark path after a single period's adjustment. This differs from sticky-price models with adjustments to lagged disequilibrium because in such models, the economy approaches the long-run path assymtotically. However, if the present model exhibited typical price adjustment to past disequilibrium then it would converge to the same path achieved in one period by the present sticky-price version.

Consider the nature of the difference in response patterns of current and expected future spot rates for purely anticipatory pricing vs. lagged disequilibrium pricing when the disturbance is believed to be a once-andfor all increase in the money supply $(p=1)$. With $p_{t}$ predetermined, the first period money-market response is the same for both pricing rules--the forward premium adjusts to clear the money market. Thus, the exact same wedge must be driven between the current and the one period expected future spot rate irrespective of the pricing rule. However, with purely anticipatory pricing the induced change in the forward premium is the exact measure of overshooting as complete adjustment is expected to be made in one period.

With pricing in response to lagged disequilibrium, price is not expected to adjust fully by next period and thus real balances are expected to be higher next period with lagged adjustment pricing than with purely anticipatory pricing. These additional real money balances require higher money demand, which is accomplished by a second period rational forward 
discount on foreign currency (i.e. $t^{E s+2}<t^{E s} s_{t+1} j$. Since this discount is rational, the spot rate must be expected to continue falling during the second period. Indeed; the argument may be extended to show that the spot rate must be expected to continue falling in all future periods until goods market equilibrium is attained.

The first period premium $\left({ }_{t} E s_{t+1}-s_{t}\right)$ is the same for both rules and both rules nave the same long run, but the lagged disequilibrium rule requires anticipated adjustments in $s_{t+j}$ for $j>1$. Hence the lagged disequilibrium rule must provide a larger immediate exchange-rate response than the purely anticipatory rule. This larger response is entirely in terms of greater overshooting.

Since the long-run response is the same for both pricing rules but the immediate response is larger for lagged disequilibrium pricing than for purely anticipatory pricing, it follows that (for the disturbance considered) for maturities greater than some length the difference in spot and forward-rate volatility must be greater under lagged disequilibrium pricing than under purely anticipatory pricing.

This result is exactly correct for $p=1$ and it will hold up for $-1 \leq \rho \leq 1$. When $|\rho|>1$, then, irrespective of the pricing rule, for maturities of forward contract greater than some length forward rates would be predicted to be more volatile than spot rates.

The example presented here gave current money market disturbances a central role. It may be though that money market disturbances do not enter the money market currently and/or that disturbances to other markets are important for exchange rate determination. First suppose that new information 
involves future values of money market fundamentals rather than current values. If such information is the source of money market disturbances then equation ( $\left.1 a^{\prime}\right)$ indicates that since innovations in future market fundamentals do not enter ( $\left.1 a^{\prime}\right)$ through $\mu_{t}$ or $p_{t}$ then the innovations must have exactly equal effects on $s_{t}$ and $t_{t+1}^{E s}$ as would be true with $s_{t}$ following a random walk. Second, suppose that disturbances to goods markets are an important source of exchange-rate volatility. (This would be true presently if $\gamma_{15}^{2} \sigma^{2} *$ were large relative to other components of equation (32).) If these goods market disturbances are uncorrelated with money market disturbances then $s_{t}$ and $t_{t}^{E s}{ }_{t+1}$ must be affected equally by such disturbances as would be true if $s_{t}$ followed a random-walk.

These last examples are not intended to suggest that exchange rates actually must follow a random walk in response to the discussed disturbances. They are only intended to point out that substantial co-movement of $s_{t}$ and $t^{E s}{ }_{t+1}$ is not ruled out by the sticky-price version.

The Flexible-Price Version

To begin studying the flexible-price version it is useful to rewrite (14) as

$$
\tilde{\mu}_{t}-s_{t}=-\alpha_{1}\left(t_{t}^{E s_{t+1}}-s_{t}\right)
$$

where $\tilde{u}_{t}=m_{t}+\alpha_{1} i *+-y_{t}+\left[s_{t}-p_{t}\right]$

since $\tilde{\mu}_{t}$ contains the nominal variable $m_{t}$ it is reasonable to suppose that disturbances to $\tilde{\mu}_{t}$ may, in part, be signals of disturbances to money growth rates. If such disturbances do signal. changes in money growth rates then 


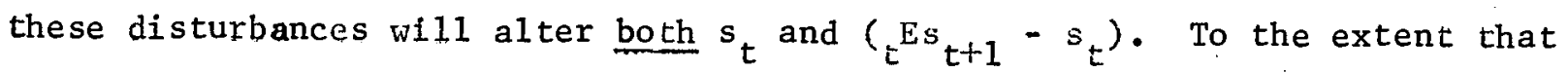
a disturbance in $\tilde{w}_{t}$ results in an unexpected increase in $\left(t_{t} s_{t+1}-s_{t}\right)$ then the disturbance's effect on $s_{t}$ will be magnified in its effect on $s_{t}$. Indeed, this is precisely the magnification effect of Frenkel (1976) and Mussa (1976)... For a magnification effect to take place though, $t_{t+1}^{E s}$ must be more volatile than $s_{t}$. This point is fllustrated in the following example. For the flexible-price version, use equation (1.7) to calculate.

$$
\begin{aligned}
& t-1 \operatorname{Var}\left(s_{t}\right)=\lambda_{12}^{2} \sigma_{v}^{2}+\lambda_{14}^{2} \sigma_{v}^{2} *+\lambda_{16}^{2} \sigma_{u}^{2} \\
& t-1 \operatorname{Var}\left({ }_{t}^{E s}{ }_{t+j}\right)=\lambda_{11}^{2} \rho^{2(j-1)} \sigma_{v}^{2}+\lambda_{14}^{2} \sigma_{v}^{2}+\lambda_{16^{\sigma} \sigma_{u}^{2}}^{2} \quad j=1,2,3, \ldots(36
\end{aligned}
$$

By inspecting the values of $\lambda_{12}$ and $\lambda_{11}$ listed in Table $I$ we find that the expiessions in (35) and (36) are exactly the same only when $0=1$. If $-1<\rho<1$ then (36) must be less than (35) for all $j$ and if $|\rho|>1$ then (36) must be greater than (35) for all $j$.

The case of $|\theta|>1$ is relevant as this is required for the magnification effect to be present. In this model, the magnification effect holds for monetary disturbances when $\lambda_{12}>1$. The magnification effect is the flexible price counterpart to overshooting in that it too explains spot-rate volatility in excess of volatillty in current market fundamentals.

\section{Some Illustrative Calculations}

The point of the present discussion is to relate the above formal models to the data. To establish such a relation (without estimating the model) assumptions need to be made about some of the model's parameters. 
In particular values of $\alpha_{1}$ and $\rho$ will be sufficient to gain some preliminary insights about the importance of magnification and overshooting effects.

In his widely cited study Goldfeld (1973) found that the combined long run interest elasticity of money demand was $-.23 .13 /$ To convert this number to a semi-elasticity 14 / we divide it by the appropriate interest rate which $I$ assume to be .08 (8 percent per year). Thus the annual semi-elasticity is 2.875 years. Presently 1 month is taken to be the relevant period and the monthly semi-elasticity is thus (2.875 years) $x(12$ months/year $)=34.5$ months, which is the value of $\alpha_{1}$ used below. To have a magnification effect present we need $\rho>1$. Further, such a nonstationary money supply process is consistent with the model only if $|\rho|<\left(\alpha_{1}+1\right) / \alpha_{1} \approx 1.03 .15 /$ The choice of $\rho$ in the range $1<\rho<1.03$ is arbitrary. The following calculations use $\rho \equiv 1.015$,

For the flexible price version we find

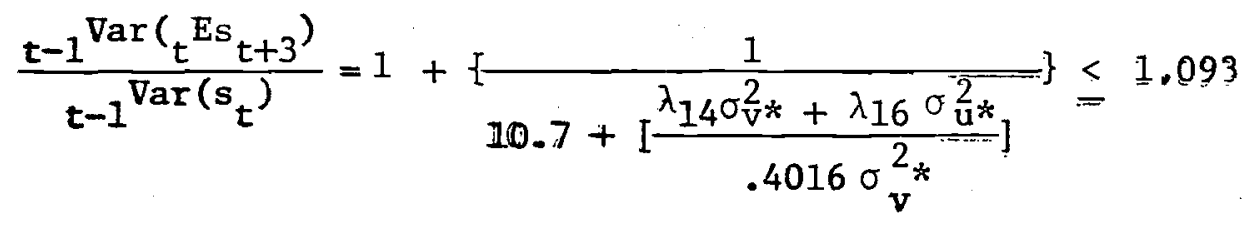

$$
\begin{aligned}
& \frac{t-1^{\operatorname{Var}\left({ }_{t} E s_{t+12}\right)}}{t-1^{\operatorname{Var}\left(s_{t}\right)}}=1+\left\{\frac{1}{2.3+\left[\frac{\lambda_{14} \sigma_{\mathrm{v}}^{2}+\lambda_{16 \sigma_{\mathrm{u}}^{2} *}^{2}}{1.8451 \sigma_{\mathrm{v}}^{2}}\right]}\right\} \leqslant 1.435
\end{aligned}
$$


Since Table III was constructed using 90 day forward rates and the calculation for ${ }_{t-1} \operatorname{Var}\left(s_{t+3}\right) /_{t-1} \operatorname{Var}\left(s_{t}\right)$ used one month as the relevant period they are of comparable dimensions. Further, the relative volatility of $t^{\text {Es }}{ }_{t+3}$ and $s_{t}$ from our illustrative calculation matches quite closely the estimated reiative volatities of the 90 day forward rates and spot rates as reported in Table III.

To obtain some idea of the importance of exchange rate overshooting It is useful to have a measure of the relative volatities of spot rates and longer term forward rates. Presently, I have obtained this measure only for Ư.S. = Canada spot and 360 day forward rates. The measure is

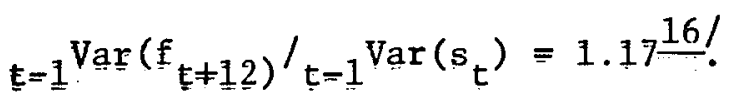

To use this measure to gain an idea of the extent of overshooting ef the U, S. = Canadian rate define

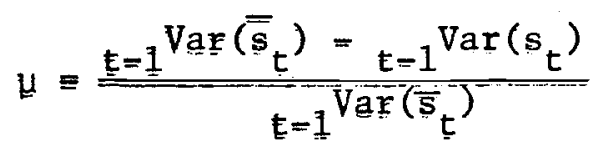

Where a bar over a variable indicates that it is interpreted as being eenditional on the stieky=price version and the absence of a bar indicates that the variable is to be interpreted as conditional on the flexible-price vefsien, Thus, tif the world is actually a sticky-price world, $\mu$ measures the fraetion of exchange rate volatility due to exchange-rate overshooting.

- Cenditional on a sticky priee world we have

$$
\frac{t=1^{\operatorname{Var}\left(\overline{\bar{f}}_{t \neq 12}\right)}}{t=1}=1.17
$$


and by manipulating (40) and using (39),

$$
\frac{t-1}{\operatorname{Var}\left(\bar{f}_{t+12}\right)-t-1} \frac{\operatorname{Var}\left(s_{t}\right)}{t-1}-\mu=.17
$$

This may be further manipulated to obtain

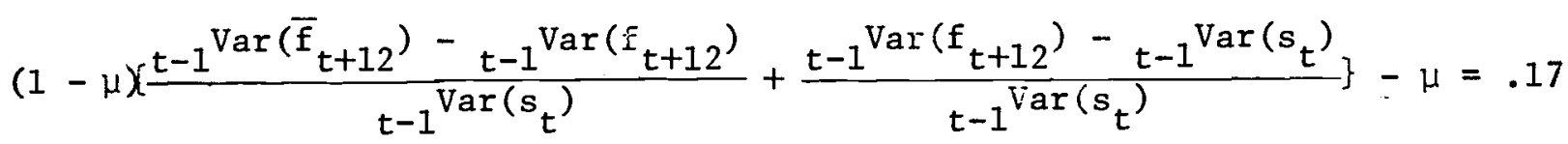

Since we are assuming $f_{t+12}={ }_{t}^{E s}{ }_{t+12}$ previous calculations (equation (38))

yield $\frac{t-1}{\operatorname{Var}\left(f_{t+12}\right)-t-1} t_{t-1}^{\operatorname{Var}\left(s_{t}\right)} \leq .435$. Further, it seems reasonable to assume that the vast bulk of all slow goods market adjustment is expected to be completed by a one year horizon implying $\overline{\mathrm{f}}_{\mathrm{t}+12} \approx \mathrm{f}_{\mathrm{t}+12}$ and $t-1 \operatorname{Var}\left(\overline{\mathrm{f}}_{\mathrm{t}+12}\right)-{ }_{\mathrm{t}-1} \operatorname{Var}\left(\mathrm{f}_{\mathrm{t}+12}\right) \approx 0.17 /$ Using these additional assumptions we find $\mu \leq .185$, which says as much as $18.5 \%$ of U.S. - Canadian exchangerate volatility may be due to exchange-rate overshooting.

It must be emphasized that the calculations in this section are intended only as a rough comparison of the models and the data. A more elaborate study would estimate the relevant behavioral parameters and parameters of the exogenous processes. However, this preliminary examination indicates that both versions of the model are roughly consistent with the data and that exchange-rate overshooting may be phenomenon of non-trivial magnitude. 


\section{Nonetary Policy and Exchange-Rete Volatility}

The modeling of previous sections presumed money to be exogenously generated by the simple autoregressive scheme of equation (10). This presumption is naive. In fact, monetary policy is dominated largely by policymakers' desires to control variables other than the money supply. Such policy is said to be activist policy, which is formalized presently by a linear moncy supply rule linking money supply movements to movements in anothar variable in the model. In this section activist monetary policy will replace the simple autoregression of previous sections.

The point to be made in this section is that if monetary policy is activist, in a realistic way, and if observers try to interpret exchange-rate volatility conditional on non-activist policy (e.g. the autoregression of past sections) then there is a natural tendency for observers to underpredict the extent of exchange-rate volatility. Such an underprediction, of course, gives the appearance of exchange-rate volatility in excess of volatility in market fundamentals.

Because the point to be made here is a point about monetary policy and not about the market for home goods a special case of the flexible-price version of the model will be adopted. To generate this special case let $B_{1} \rightarrow \infty$ in equation (6). The goods and money markets thus collapse to

$$
m_{t}-s_{t}=\alpha_{0}-\alpha_{1}\left(i{ }_{t}^{*}+t_{t+1}^{E s}-s_{t}\right)
$$

We continue to assume $i_{t}^{*}=i \underset{t-1}{*}+v_{t}^{*}$ but now impose

$$
m_{t}-m_{t-1}=\bar{m}+\delta_{1}\left({ }_{t-1} \Delta^{i}{ }_{t}\right)+v_{t},
$$


where ${ }_{t-1} \Delta x_{t} \equiv x_{t}-{ }_{t-1} E x_{t}$ is the innovation operator and $v_{t}^{*}$ and $v_{t}$ are mutually and serially uncorrelated disturbances having zero means ani finite variances, $\sigma_{v}^{2}$ and $\sigma_{v}^{2}$ respectively.

Notice that we can write (44) as

$$
\begin{aligned}
& \mathrm{m}_{t}=\bar{m}+\mathrm{m}_{t-1}+\tilde{v}_{t}, \\
& \tilde{v}_{t}=\delta_{1}\left(t_{t-1} \Delta_{t}\right)+v_{t} .
\end{aligned}
$$

and since $\tilde{v}_{t}$ is orthegonal to all variables dated $t$ - 1 or earlier, a researcher investigating the time series behavior of money, conditional on exogenity, would not discover the true nature of $\tilde{v}_{t}$ and would interpret $\tilde{v}_{t}$ as a monetary innovation uncorrelated with the model's other disturbances.

The example at hand has been cooked-up to provide ease of computations. Kate that expected money growth, $t^{E\left(m_{t+1}-m_{t}\right)}$ is the constant $\bar{m}_{\text {. With }}$ rational expectations, this implies that $t^{E\left(s_{t+1}-s_{t}\right)}$ is also a constant. Hence, the innovation operator applied to $(43)$ yields

$$
\tilde{v}_{t}-t_{t-1}^{\Delta s} t=-v_{1} v_{t}^{*}
$$

which is

$$
t-1 \Delta s_{t}=\ddot{v}_{t}+\alpha_{1} v_{t}^{*}
$$

It follows that

$$
\left.t-1 \operatorname{\nabla ar}_{t}\right)=s_{t-1} \operatorname{\nabla ar}\left(\tilde{\nabla}_{t}+\alpha_{1}^{\nabla} \nabla_{t}^{*}\right)
$$

An investigator believing $\tilde{\nabla}_{t}$ to be a monetary disturbance uncorrelated with would predict 


$$
t-1 \text { Var }\left(s_{t}\right)^{n}={ }_{t-1} \operatorname{Var}\left(\tilde{v}_{t}\right)+\alpha_{1}^{2} \sigma_{v}^{2} *
$$

with the model requiring.

$$
\operatorname{tin}_{1} \operatorname{Var}\left(\tilde{v}_{t}\right)=\delta_{1}^{2} \sigma_{v}^{2} *+\sigma_{v}^{2}
$$

Thus, the naive prediction of exchange-rate volatility is

$$
\left.\underline{t-1} \operatorname{Var}_{\underline{t}}\right)^{n}=\left(\delta_{\underline{1}}^{2}+\alpha_{1}^{2}\right) \sigma_{v}^{2} *+\sigma_{v}^{2}
$$

However, $\tilde{v}_{t}$ is aetually correlated with $v_{t}^{*}$ and hence, properly computed (49) yields

$$
\tan \left(s_{t}\right) \equiv\left(\delta_{1}+\alpha_{1}\right)^{2}+\sigma_{v}^{2}
$$

The relative difference of (52) and (53) is

$$
\frac{t-1^{\operatorname{Var}\left(s_{t}\right)-t_{-1} \operatorname{Var}\left(s_{t}\right)^{n}}}{t-1^{\operatorname{Var}\left(s_{t}\right)^{n}}}=\frac{2 \delta_{1} \alpha_{1} \sigma_{v}^{2} *}{\left(\delta_{1}^{2}+\alpha_{1}^{2}\right) \sigma_{v}^{2}+\sigma_{v}^{2}}
$$

When polfey makers atempt to stabilize interest rates they make $\delta_{1}$.positive, Implying that (54) must be positive. The size of (54) depends on the size of $\sigma_{v}^{2} v_{v}$ lattve to $\sigma_{v}^{2}$ and on the relationship of $\delta_{1}$ to $\alpha_{1}$. In the most extreme ease, $\sigma_{\mathrm{v}}^{2} / \theta_{\mathrm{v}}^{2} * 0$ and $\delta_{1} \equiv \alpha_{1}$ implying that the naive prediction misses $50 \%$ of the variability of exchange rates.

The above example is simple but its point, which is that price vartability depends on elasticities of excess demand and the variability of underlying exogenous disturbances, is robust to a range of alternative opectfieations. First consider the response of the sticky price version to forelgn interest rate disturbance. If (44) now governs the money 
supply then the interest rate disturbance brings abonc a monetary innovation which alters excess demand for money in the same direction as the interest rate disturbance alters the excess demand. This excess demand is balanced and partially offset by overshooting which induces a change in the forward premium. The extent of overshooting however is exacerbated by the covariation of monetary and foreign interest rate innovations.

Second, suppose that money growth responds negative1y to output innovations. If so, then an output innovation will raise money demard and reduce money supply requiring a larger exchange rate innovation to clear the money market than would be needed if monetary growth were exogenous to output disturbances. Third, in the above it has been assumed that money growth responds only to innovations in endogenous variables. Since the levels of those endogenous variables must contain their innoyations the argument would not be much altered if (44) were to depend on the level of $i_{t}$ relative to a target.

\section{Some Policy Implications}

The present analysis illustrates two well known policy implications of the asset market approach to the foreign exchange market (see e.g. Frenkel and Mussa (1980)). First, nonstationary growth or money (relative to income) produces magnification of the exchange-rate effects of monetary disturbances and thus produces high volatility of exchange rates relative to the volatility of monetary disturbances. Thus, policy makers desiring to reduce exchange-rate volatility might well look toward stabilizing the money supply process. 
Second, exchange rates are only a portion of the set of macrovariables which concern policy makers, who operate using a limited set of tools. Concentration of policy on stabilizing variables other than exchange rates can render exchange rates more volatile than they otherwise would have been. Thus, policy making with many "targets" but limited "tools" requires coherent policy not a piece meal of "exchange rate policy" and (for example) "interest rate policy."

\section{Concluding Remarks}

Four main points ernerge in this paper:

(i) The failure of purchasing power parity is a phenomenon having features reconcilable with either sticky-price or flexible-price models. The feature examined in detail presențly, volatility of exchange rates in excess of volatility in national price levels. required Identical conditioning of the sticky-price and flexible-price versions.

(ii) The fact that spot exchange rates and contemporaneous forward fates for maturities of up to one year track each other so well is a striking regularity, which is not necessarily predicted by popular models of the foreign exchange market. It was seen that while spot and forward rates may move elosely together their volatility is quite different with forward fates being more volat 11e than spot rates. Once we allow a nonstationary money suppiy, the flexible price version predicts more volatility in Earward rates than in spot rates. Further, the sticky price version is also consisteat with this regularity for forward maturities longer than one month. 
(iii) At the outset of the Asset Market Approach to exchange rates Mussa (1976) pointed out the sufficiency of treating the money supply as "an arbitrarily prescribed stochastic process, a stochastic black box'10/ when modeling agents' beliefs about the rate of change of the exchange rate. While this point is correct for the first moment of the exchange-rate distribution, it is not correct for understanding higher moments of exchange-rate distributions, eg. volatility. The precise stochastic structure of the money supply process can be evefy bit as important as the structure of money

- demand for understanding the volatility of exchange rates.

(iv) The explanations of exchange-rate volatility studied here naturally compete for professional priority but they are in no way mutually exclusive. Hence, it would be unsurprising to find all present, in some measure, in a satisfactory explanation of exchange-rate volatility. 


\section{APPENDIX A}

Comparing the Kouri and the Frenkel-Mussa Models

The model in section $\mathrm{V} \cdot$ may be written as

$$
m_{t}-s_{t}=\alpha_{0}-\alpha_{1}\left(i \psi_{t}+{ }_{t}^{E s_{t+1}}-s_{t}\right)+z_{t}
$$

where $z_{t}$ is some variable affecting money demand. Manipulate (A1) to yield

$$
\left.s_{t}=\frac{-1}{1+\alpha_{1}} \sum_{j=0}^{\infty} t^{E\left\{\alpha_{0}-\alpha_{1}{ }^{*} t_{t+j}\right.}+\left(z_{t+j}-m_{t+j}\right)\right\}\left(\frac{\alpha_{1}}{1+\alpha_{1}}\right) j
$$

Suppose that $v_{t}$ is a eurrent monetary disturbance then the magnification effect requires

$$
\left.\left.\frac{d s_{t}}{d v_{t}}=\frac{-1}{1+\alpha_{1}} \sum_{j=0}^{\infty} t \frac{d\left(z_{t+j}-m_{t+j}\right)}{d v_{t}}\right\} \frac{\alpha_{1}}{1+\alpha_{1}}\right)^{j}>1
$$

In the examples eonsidered by Mussa $t_{t+j}^{E d z}{ }_{t+v_{t}}=0, j=0,1,2 \ldots$, and thus these examples involved magnifieation due entirely to money growth.

The Kouri vergion of this model would define

$$
z_{t}=\lambda\left(m_{E}-g_{E}\right) \neq(1-\lambda) k_{t}, \quad 0<\lambda<1,
$$

with $z_{t}$ having the interpretation of the logarithm of real marketable wealth and $k_{t}$ being real net fereign assets. A1though (A3) is invariant to the definition of $\mathrm{z}_{\mathrm{E}}$ it is useful to use (A4) to write (A1) as

$$
m_{t}-s_{t} \equiv(1-\lambda)^{-1}\left[\alpha_{0}-\alpha_{1}\left(i_{t}+t_{t+1}^{E s}-s_{t}\right)\right]+k_{t},
$$

which may be manipulated to yield 


$$
\begin{aligned}
& s_{t}=\frac{-1}{1+\delta} \sum_{j=0}^{\infty} t E\left\{(1-\lambda)^{-1}\left(\alpha_{0}-\alpha_{1} i \psi_{t+j}\right)+\left(k_{t+j}-m_{t+j}\right)\right\}\left(\frac{\delta}{1+\delta}\right)^{j}: \\
& \delta \equiv \alpha_{1}(1-\lambda)^{-1}
\end{aligned}
$$

From (A6) it is apparent that the magnification effect requires

$$
\frac{d s_{t}}{d v_{t}}=\frac{-1}{1+\delta} \sum_{j=0}^{\infty} t E\left[\frac{d\left(k_{t+i}-m_{t+i}\right)}{d v_{t}}\right\}\left(\frac{\delta}{1+\delta}\right)^{j}>1 .
$$

(A7) does not differ from (A3); it is (A3) written using the definition (A4). The interesting examples which have used the Kouri version have not imposed $d k_{t+j} / d_{t}=0, j=1,2, \ldots$, indeed the centerpiece of these studies is the current account which governs the evolution of $\mathrm{k}_{t}$. Thus, the difference between examples using the Frenkel-Mussa and Kouri versions centers on emphasis with the Frenkel-Mussa version concentrating on the time path of $\mathbf{m}_{t+j}$ and the Kouri yersion concentrating on the time path of $k_{t+j}-m_{t+j}$. The 1itgerature eontains other examples of the $z$ variable where $d_{t} E z_{t+j} / d v_{t} \neq 0 j \equiv 0,1,2 \ldots$, eg. Flood (1979a) who makes output endogenous. 
APPENDIX B

The data used in this paper are derived from the Division of International Finance Data Base, maintained by the Board of Governors of the Federal Reserve System. The Data Base provides daily spot exchange rate time series expressed in U.S. cents per national currency unit. From these data, monthly spot rate time series, $s(i, j)$, were constructed where $i, j$ are counters over the country set (U.S., Canada, Germany, Japan, Switzerland, U.K.) and $i$ represents the denominating currency. For $i=U . S .$, this series consists of the log of the daily spot rate prevailing on the $n$th trading day of every month of $x$ total trading days where

$n=x / 2$ for montins ifith an ever nurber of trading days $n=(x / 2)+.5$ for months with an odd number of trading days.

For $i \neq U . S ., s(i, j)=s(U, S ., j)-s(U . S,, i)$.

The Data Base also provides daily 90 day forward exchange rate time series expressed in premium values. These series were first converted to level rates and then used to construct monthly series, $f(i, j)$, as above. The consumer price indices used in this paper, $p(j)$, are monthly time series taken directly from the Data Base:

United States CPI

Canada CPI, all items

Germany CPI, cost of living index

Japan-National CPI .

Switzerland Consumer Price Index--total

United Kingdom Retail Price Index.

In all cases, the data are seasonally unadjusted.

For country sets where $i$ or $j=$ Germany, $s(i, j), f(i, j)$, and $p(j)$ extend from January, 1975 to November, 1979. inclusive. For all other sets, the time series extend from October, 1974 to November, 1979 inclusive. 


\section{References}

Bilson, J.

(1978) "Rational Expectations and the Exchange Rate", in Jacob

Frenkel and Harry Johnson (eds.) The Economics of Exchange.

Rates, Addison-Wesley, Reading, MA.

(1979) "The Deutsch Mark/Dollar Rate: A Monetary Analysis", in

Karl Brunner and Allan Meltzer (eds.) Policies For Employment,

Prices and Exchange Rates, Volume 11 Carnegie-Rochester

Conference Series on Public Policy, North-Holland, Amsterdam.

(1980) "The Speculative Efficiency Hypothesis", Working Paper N.B.E.R., Cambridge, MA.

Boyer, R, and Hodrick, R.

(1980) "Perfect Foresight, Financial Policies, and Exchange Rate Dynamics", Working Paper 53-79-80, G.S.I.A., Carnegie-Me11on University, Pittsburg, PA.

Dornbusch, R.

(1976) "Expectations and Exchange Rate Dynamics," Journal of Political Economy, pp. 1161-76. , and Fischer S.

(1980) "Exchange Rates and the Current Account", American Economic Review, pp. 960-72.

Flood, R.

(19.79a) "Capital Mobility and the Choice of Exchange Rate System," International Economic Review, pp. 405-16. 
(1979b) "An Example of Exchange Rate Overshooting," Southern Economic Journa1, pp. 168-78. and Garber P.

(1980) "An Economic Theory of Monetary Reform," Journal of Political Economy, pp. 24-58. and Marion, N.

(1980a) "The Transmission of Disturbances Under Alternative ExchangeRate Regimes with Optimal Indexing," N.B.E.R. Working Paper 500, Cambridge, MA.

Frankel, J.

(1979) "On the Mark: The Theory of Floating Exchange Rates Based on Real Interest Differential," American Economic Review 69, 610-23.

Frengẹe1, J.

(1976) "The Monetary Approach to the Exchange Rate: Doctrinal Aspects and Empirical Evidence," Scandinavian Journal of Economics, 78 no. 2, pp. 202-24.

(1977) "The Forward Exchange Rate, Expectations, and the Demand for Money: The German Hyperinflation," American Economic Review 67, pp. 653-70.

(1980a) "Flexible Exchange Rates in the 1970's," N.B.E.R. Working Paper 450, Cambridge, MA. 
(1980b) "The Collapse of Purchasing Power Faritjes in the 1970's," Working Paper, University of Chicago, Chicago, IL. and Mussa, M.

(1980) "Efficiency of the Foreign Exchange Market and Measures of Turbulence," American Economic Review 70, pp. 374-81. and Rodriguez, C.

(1980) "Exchange Rate Dynamics and the Overshooting Hypothesis," Working Paper, University of Chicago, Chicago, IL.

Garber, P.

(1978) "Efficiency in Foreign Exchange Markets: Interpreting A Common Technique," Working Paper, University of Vịginina, Charlottesville, VA.

Goldfeld, S.

(1973) "The Demand for Money Revisited," Brookings Papers on Economic Activity, 3, pp. 577-638.

Hakkio, C.

(1980) "Expectations and the Forward Exchange Rate," N,B,E,R. Werking Paper 439, Cambridge, MA.

Hansen, L. and Hodrick, R. .

(1979) "Forward Exchange Rates as Optimal Predictors of Futufe Spot

Rates: An Econometric Analysis," Working Paper, G.S.I.A., Carnegie-Mellon University, Pittsburg, PA.

Isard, $\mathbf{P}$.

(1977) "How Far Can We Push the Law of One Price," American Economie Review, $942-49$. 
Kouri, P.

(1976) "The Exchange Race and the Balance of Payments in the Short Run and in the Iong Run," Scandinavian Journal of Economics, 78, no. 2, pp. 280-304.

Kravis, I. and Lipsey, R.

(1978) "Price Behavior in Light of Balance of Payments Theories," Journal of International Economics, 193-247.

Krugman, P.

(1978) "Purchasing Power Parity and Exchange Rates," Journal of International Economics 8, 397-407.

Magee, S.

(1978) "Contracting and Spuricus Deviations from Purchasing Power

Par1ty," in J. Frenkel and H. Johnson (eds.) The Economics of

Exchange Rates, Addision-Wesley, Reading, MA.

McCaI11im, B.,

(1980) "Rational Expectations and Macroeconomic Stabilization

Policy," Working Paper, University of Virginia, Charlottesvilie, VA.

Yeese, $R$, and Singleton, $K$.

(1980a) "Rational Expectations and the Volatility of Floating Exchange Rates, Working Paper, Board of Goverzors of the Federa1 Reserve, Washingtion, D.C.

(19800) "Rational Expectations, Risk Premia and the Market for Spot axd Forward Exchange." Working Paper. Board of Governors of the Federal Reserve. Wasinington, D.C. 
Mussa, M.

(1976a) "The Exchange Rate, The Balance of Payments and Monetary and Fiscal Policy Under a Regime of Controlled Floating," Scandinavian Journal of Economics, 78, no. 2, pp. 229-48.

(1976b) "Sticky Prices and Disequilibrium in a Rational Model of the Inflationary Process," Working Paper, University of Chicago, Chicago, IL.

(1977) "Real and Monetary Factors in a Dynamic Theory of Foreign Exchange," in M. Artis and A. Nobay (eds.) Studies in Economic Analysis, 0xford.

(1979). "Empirical Regularities in the Behavior of Exchange Rates and Theories of the Foreign Exchange Market," in $\mathrm{K}$. Brunner and A. Meltzer (eds.), Policies for Employment, Prices and Exchange Rates, North-Holland, Amsterdam, pp. 9-57.

Rogoff, K.

(1979) Essays on Exchange Rate Volatility, Ph.D. Thesis, M.I.T., Cambridge, MA. .

Stockman, A.

(1980) "A Theory of Exchange Rate Determination," Journal of Political Economy 88, pp. 673-98. 
Wilson, C.,

(1979) "Anticipated Shocks and Exchange Rate Dynamics," Journal of Political Economy, pp. 639-47.

Wyplosz, C.,

(1980) "The Exchange and Interest Rate Term Structure Under Risk Aversion and Rational Expectations," Working Paper, INSEAD, Fontainbleau, France. 


\section{FOOTNOTES}

If Definitions of many terms used in the introduction (eg. volatility) are contained in later sections.

2/ Equation (1) may be written as

$$
m_{t}-p_{t}=\alpha_{0}-p_{1} i_{t}+\alpha_{2} y_{t}+\left(\alpha_{2}-1\right)(1-\theta)\left(p_{t}-q_{t}\right)
$$

The assumption $\alpha_{2}=1$ allows us to ignore $\left(p_{t}-q_{t}\right)$ in money demand. The influence of $\left(p_{t}-q_{t}\right)$ is proportional to $\left(\alpha_{2}-1\right)$ times the share of foreign goods in domestic consumption, which is the product of two small (< .5) fractions. An equivalent simplification, followed by Dornbusch (1976), is to deflate nominal money and nominal income by $P_{t}$ rather than $\pi_{t}$. 3/ This empirical work is exemplified by Bilson (1980), Frenkel (1977), Garber (1978), Hakkio (1980), Hansen and Hodrick (1979), and Meese and Singleton (1980b).

4/ Wyplosz (1980) has modeled a time-varying risk premiums in a maximizing model of an open economy. 
5/ Instead of assuming domestic output to be constant it may be assumed that output depends positively on relative price (sce Flood and Marion (1980) Appendix 5) in which case $\beta_{1}$, in (6), would be interpreted as an excess demand elasticity.

6/ Mussa's (1976b) pricing rule may be written as

$$
p_{t}-p_{t-1}=\delta\left(\hat{p}_{t-1}-p_{t-1}\right)+{ }_{t-1} E\left(\hat{p}_{t}-\hat{p}_{t-1}\right)
$$

where $\hat{p}_{t+j}$ is the price which would clear the goods market at $t+j$. With $\delta=I$ and ${ }_{t-1} \hat{E p}_{t-1}=\hat{p}_{t-1}$ Mussa's rule is $p_{t}={ }_{t-1} \hat{E p}_{t}$, which is the rule used in the present sticky-price version. Our pricing rule would also result if output adjustment costs were zero in McCallum's (1980) model. II Flood (1979a) and Flood and Marion (1980a) have been critical of the methodology of ignoring correlations among foreign variables. Presently though, accounting for such correlations adds much complication without much illumination and thus they are ignored.

8/ Normally sticky-price models include at least one past price among the set of state variables. The assumption of purely anticipatory pricing is attractive analytically because past price is irrelevant to the current pricing decision.

9/ A conditional variance is used as the present measure of volatilfty to accommodate a later discussion of a nonstationary. money supply's effect on the exchange rate. Nonstationary money causes a nonstationary exchange rate and the unconditional variance does not exist for a nonstatonary series. Previous discussions involving exchange rate volatility (e.g., 
Biison (1978), Mussa (1976), Dornbusch (1976)) have assumed nonstationary money supply processes and thus if exchange rate variances were calculated they would have had to be conditional variances.

10/ Since the C.P.I. is an average of prices sampled during the month and the exchange rate is sampled at a point in time there is a natural tendency for the exchange rate to be more volatile than a C.P.I. ratio. As a crude correction for this problem I recomputed the U.S. - Canada entry in Table II using a monthly average spot rate instead of a point in time spot rate. The result was a volatility ratio of 8.5 rather than the 16.6 reported in Table II. Since the relative volatility of 8 continued to match the regularity reported, this approach was discarded as being redundant.

11/ Similar results are reported by Stockman (1980).

12/ The analysis of this section is based on the empirical regularities summarized in Table III. It thus has a different basis than the variance bounds work of Meese and Singleton (1980b) who derive upper bounds on exchange rate variance using the error orthoganality property of optimal forecasts. In the discussion that follows, one month will be taken as the relevant period. Thus $\mathrm{f}_{\mathrm{t}+3}$ refers to a forward exchange rate quoted at time $t$ for execution 3 months hence.

13/ Goldfeld found that the long run elasticity for the interest rate on time deposits was -.16 and that for the interest rate on commercial paper was -.067 . Thus the combined interest elasticity is $-.227 \approx-.23$ (Goldfeld, p. 602 Regression A). 
14/ The present model assumes that money demand is semi-log linear, i.e., the log of real money demand, $m_{t}-p_{t}$, is linearly related to the level of the interest raie, $i_{t}$. Since $i_{t}$ has a time dimension (e.g. 10 percent per year) the semi-elasticity must also have a time dimension (e.g. years) so that their product $\left(\alpha_{1} i_{t}\right)$ is units free.

15/ Flood and Garber (1980) refer to this requirement as process

\section{consistency.}

16/ The number 1.17 is the ratio of the sum of squared residuals in regression $\mathrm{F}_{12}$ to the sum of squared residuals in regression $\mathrm{S}$, where $\mathrm{F}_{12}$ is an olsq regression of the 12 month (360 day) U.S. - Canada forward rate at time $t$ on a linear trend and the information set $\Delta(t-1)$. $S$ is an olsq regression of the U.S. Canada spot rate at time $t$ on a linear trend and the information set $\Delta(t-1) . \Delta(t-1)$ is a vector of variables which consists of

$$
\begin{aligned}
& \Delta(t-1)=\left\{s(t-i) ; i=1,2,3,4 ; f_{t+1}(t-i), i=1,2,3,4 ;\right. \\
& f_{t+3}(t-i), i=1,2,3,4 ; f_{t+12}(t-i), i=1,2,3,4 ; \\
& \left.p(t-i), i=1,2,3,4 ; p^{*}(t-i), i=1,2,3,4\right\},
\end{aligned}
$$

where

$$
\begin{aligned}
& s(t-i)=\text { In U.S./Canada spot rate at } t-i \\
& f_{t+1}(t-i)=\text { In U.S./Canada } 30 \text { day forward rate at } t-i \\
& f_{t+3}(t-i)=\text { In U.S./Canada } 90 \text { day forward rate at } t-i \\
& \frac{f+12}{(t-i)}=1 \text { In U.S./Canada } 360 \text { day forward rate at } t-i \\
& p(t-i)=\text { In Canadian C.P.I at } t-i \\
& p *(t-i)=\text { In U.S. C.P.I. at } t-i .
\end{aligned}
$$

Data sources are reported in the Appendix. 
17/ With purely anticipatory pricing and a tine period of one month $\bar{f}_{t+12}=f_{t+12}$. However, in general, adjustment might be expected to be somewhat slower than the one period adjustment assumed for purely anticipatory pricing. If adjustment is slower, then $\bar{f}_{t+12}$ would be more volatile than $f_{t+12}$ and by assuming equal volatility we understate the extent of exchange rate overshooting. Since $\bar{E}_{t+j} \rightarrow f_{t+j}$ as $j$ becomes large, in most models, it is appropriate to use forward contracts of long maturity to measure exchange-rate overshooting.

18/ See Mussa 1976a, pp 247. 